\title{
Genetic linkage of autosomal dominant primary open angle glaucoma to chromosome $3 q$ in a Greek pedigree
}

\author{
George Kitsos $^{1}$, Hans Eiberg ${ }^{2}$, Effrosini Economou-Petersen ${ }^{3}$, Mary K Wirtz ${ }^{4,5}$, \\ Patricia L Kramer ${ }^{6}$, Miltiadis Aspiotis ${ }^{1}$, Niels Tommerup ${ }^{2}$, Michael B Petersen*,7 and \\ Konstantinos Psilas ${ }^{1}$
}

\author{
${ }^{1}$ Department of Ophthalmology, University of Ioannina, Ioannina, Greece; ${ }^{2}$ Institute of Medical Biochemistry and \\ Genetics, University of Copenhagen, Copenhagen, Denmark; ${ }^{3}$ Drakopoulion Blood Bank Center, Athens, Greece; \\ ${ }^{4}$ Department of Ophthalmology, Casey Eye Institute, Oregon Health Sciences University, Portland, USA; \\ ${ }^{5}$ Department of Molecular and Medical Genetics, Oregon Health Sciences University, Portland, USA; ${ }^{6}$ Department \\ of Neurology, Oregon Health Sciences University, Portland, USA; ${ }^{7}$ Department of Genetics, Institute of Child \\ Health, Athens, Greece
}

\begin{abstract}
A locus for juvenile onset open angle glaucoma (OAG) has been assigned to chromosome 1q in families with autosomal dominant inheritance (GLC1A), due to mutations in the TIGR/MYOC gene. For adult onset OAG, called primary open angle glaucoma or POAG, five loci have so far been mapped to different chromosomes (GLC1B-GLC1F). Except for the GLC1B locus, the other POAG loci have so far been reported only in single large pedigrees. We studied a large family identified in Epirus, Greece, segregating POAG in an autosomal dominant fashion. Clinical findings included increased cup to disc ratio (mean 0.7), characteristic glaucomatous changes in the visual field, and intraocular pressure before treatment more than $21 \mathrm{mmHg}$ (mean $31 \mathrm{mmHg}$ ), with age at diagnosis 33 years and older. Linkage analysis was performed between the disease phenotype and microsatellite DNA polymorphisms. Linkage was established with a group of DNA markers located on chromosome 3q, where the GLC1C locus has previously been described in one large Oregon pedigree. A maximal multipoint lod score of 3.88 was obtained at marker D3S1763 (penetrance $80 \%)$. This represents the second POAG family linked to the GLC1C locus on chromosome 3q, and haplotype analysis in the two families suggests an independent origin of the genetic defect. European Journal of Human Genetics (2001) 9, 452-457.
\end{abstract}

Keywords: glaucoma; POAG; autosomal dominant inheritance; linkage analysis; chromosome 3q; GLC1C

\section{Introduction}

Glaucoma is a progressive optic neuropathy characterised by optic nerve degeneration leading to a characteristic excavation of the optic disc and a typical visual field impairment. ${ }^{1,2}$ Whereas treatable in the early stages, often it is undiagnosed and not treated in time, which results in irreversible blindness (the 'silent blinder'). Glaucoma is the second

${ }^{*}$ Correspondence: Dr MB Petersen, Department of Genetics, Institute of Child Health, 'Aghia Sophia' Children's Hospital, GR-115 27 Athens,

Greece. Tel: +3017753 030; Fax: +30 17700 111;

E-mail: inchildh@otenet.gr

Received 1 September 2000; revised 26 February 2001; accepted 27 February 2001 leading cause of blindness worldwide. ${ }^{2}$ It is a heterogeneous group of disorders, the majority of which are associated with an open, normal appearing anterior chamber angle with normal trabecular meshwork and are termed open angle glaucoma (OAG). ${ }^{1,2}$ Ageing is a risk factor for glaucoma, as illustrated by a prevalence of OAG in the white population smaller than $1 \%$ for ages below 50 years and $1-2 \%$ for the population over age 40 years. ${ }^{3-6}$ Age-adjusted prevalence rates are four to five times higher in blacks as compared with whites. $^{7}$ OAG is likely to be a genetically heterogeneous disorder that results from the interaction of multiple affected genes and environmental influences. Positive family history is an important risk factor for development of the disease, ${ }^{8,9}$ with a lifetime risk of glaucoma of $22.0 \%$ in first-degree 
relatives of patients in a population-based study. ${ }^{9}$ The relatively late age at onset of most forms of OAG has complicated the efforts to identify the mode of inheritance and the genes involved, but segregation analysis in several adult onset pedigrees has shown autosomal dominant inheritance. ${ }^{10-12}$

Traditionally, OAGs have been subclassified according to age at onset and severity. Juvenile onset OAG (JOAG) usually arises before 35 years of age and is an aggressive disorder, whereas adult onset $\mathrm{OAG}$, also known as primary OAG (POAG), occurs after the age of 40 years and is insidious. A locus for JOAG (GLC1A) was assigned to the long arm of chromosome 1 in a large family with autosomal dominant inheritance. ${ }^{13}$ The responsible gene was later shown to be the trabecular meshwork-inducible glucocorticoid response protein (TIGR) or myocilin gene (MYOC) located at 1q23q24. ${ }^{14,15}$ Mutations in the TIGR/MYOC gene have subsequently been detected in most familial cases of JOAG as well as in a small proportion (3-5\%) of POAG patients. ${ }^{16,17}$ The clinical features associated with these mutations show a wide range (age at diagnosis ranging from 8 to 77 years and maximal recorded intraocular pressures (IOPs) ranging from 12 to $77 \mathrm{mmHg}){ }^{16}$ For POAG, five loci have so far been mapped by linkage analysis in families with autosomal dominant mode of inheritance and age-dependent penetrance: GLC1B to 2 cen-q13, ${ }^{18}$ GLC1C to $3 q 21-q 24,{ }^{19}$ GLC1D to $8 \mathrm{q} 23,{ }^{20}$ GLC1E to $10 \mathrm{p} 15-\mathrm{p} 14,{ }^{21}$ and GLC1F to $7 \mathrm{q} 35-\mathrm{q} 36,{ }^{22}$ showing the high degree of genetic heterogeneity in POAG. Except for the GLC1B locus, the other POAG loci have so far been reported only in single large pedigrees, and their contribution to POAG worldwide has therefore not been established. A genome scan for POAG susceptibility genes using affected sibpairs has furthermore shown significant results on chromosomes $2,14,17$, and $19 .{ }^{23}$

We present clinical and genetic mapping data confirming the assignment of a locus for autosomal dominant POAG to chromosome 3q (GLC1C) in a large Greek pedigree, where we previously excluded linkage to the juvenile glaucoma locus on chromosome $1 \mathrm{q}$ (GLC1A). ${ }^{24}$ This family therefore represents the second family linked to this locus.

\section{Materials and methods}

A large pedigree had previously been ascertained through the registry of the Department of Ophthalmology, University of Ioannina, Greece. ${ }^{24}$ This and several other families with autosomal dominant POAG had previously been identified, living in the North Western district of Greece (Epirus). ${ }^{12}$ For the present study, DNA samples were available from 50 individuals from one large family, including 10 affected individuals (Figure 1). All individuals aged 30 years or more and living in Greece were examined by one of us (G Kitsos). The clinical examination included visual acuity, slit-lamp examination, applanation tonometry, gonioscopy, ophthal-

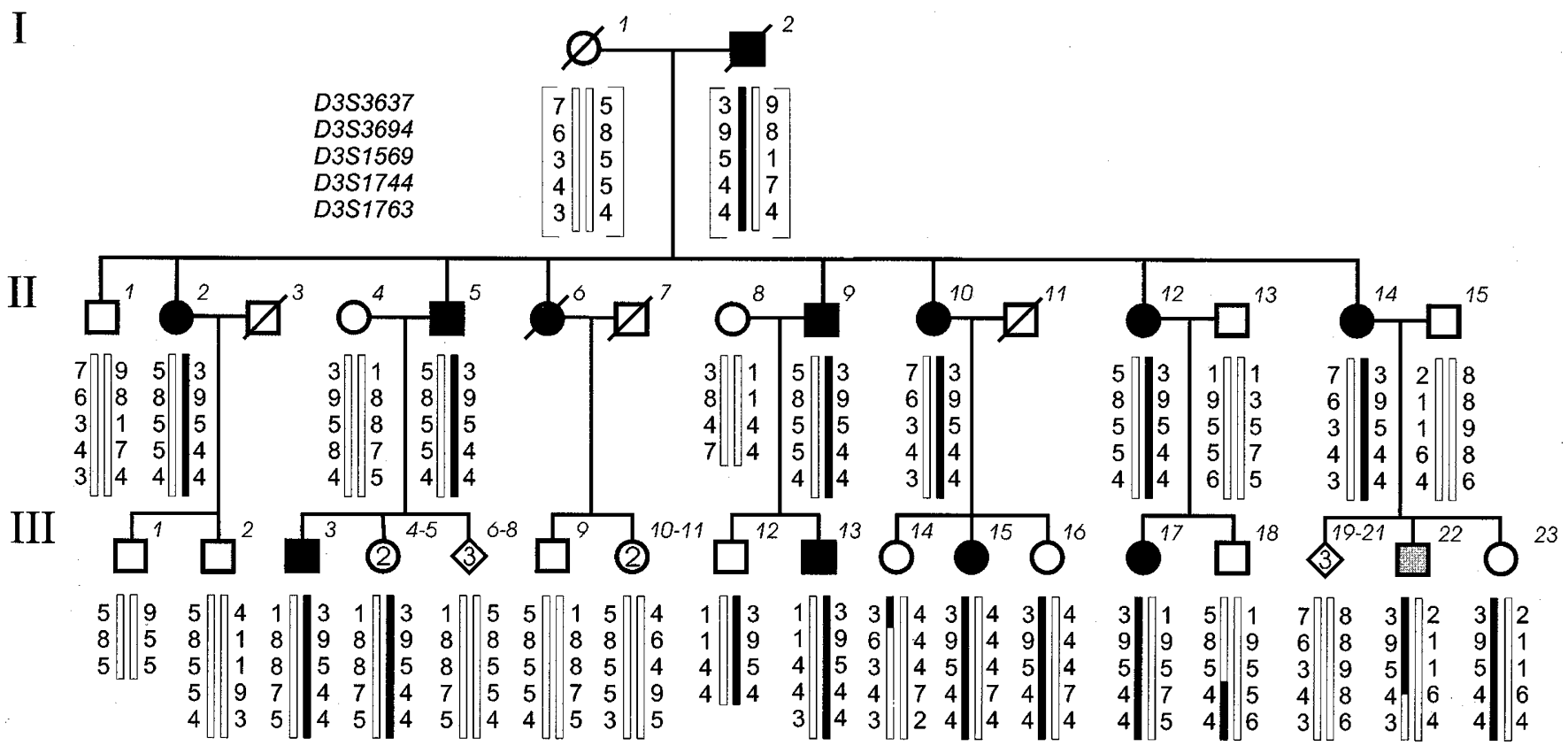

Figure 1 Pedigree of the Epirus family segregating POAG. Solid squares and circles=affected, open symbols=unaffected family members, shaded symbol=disease status unknown. The two bars below each individual correspond to the haplotypes in chromosomal region 3q21-q24 with numbers corresponding to the respective alleles at the microsatellite loci studied as indicated at the top left of the pedigree. The haplotype segregating with the POAG phenotype (3-9-5-4-4), indicated by the black bar, corresponds to allele sizes 194-140-287-143-272 in base pairs. 
moscopy with evaluation of the optic disc and determination of the cup to disc ratio, and visual field test (Humphrey Visual Field Analyzer). The clinical criteria used to classify the patients as affected with POAG were evidence of glaucomatous optic nerve damage (including thinning or notching of the neuroretinal rim of the disc, progressive increase in cupping of the optic nerve (cup to disc ratio $>0.6$ ), acquired pit of the optic nerve, retinal nerve fibre layer defects, and flame-shaped haemorrhage crossing the outer edge of the disc), visual field impairment (including arcuate defect, nasal step, paracentral scotoma, and generalised depression) in the absence of other causes of the field defect, and normal appearing, open anterior chamber angles (grades III or IV, according to the Shaffer grading system) without signs of congenital, secondary or angle closure glaucoma. ${ }^{25}$ Elevated IOP (above $21 \mathrm{mmHg}$ ) is no longer part of the definition, as about $30-50 \%$ of POAG patients have IOP levels below $21 \mathrm{mmHg}$, but is a major cause of development of glaucomatous optic nerve damage. ${ }^{25}$ One individual with ocular hypertension without clinical glaucoma (III-22) was classified as unknown for the linkage analysis. The visual field defect in the patients was classified as severe or moderate according to previously described criteria. ${ }^{26}$

After excluding linkage to the juvenile glaucoma locus on chromosome $1 \mathrm{q},{ }^{24}$ we searched for linkage in our pedigree to the known POAG loci. Oligonucleotide sequences flanking microsatellite DNA polymorphisms were as published elsewhere. ${ }^{27}$ Polymerase chain reaction (PCR) amplification of genomic DNA using end-labelling of primer with ${ }^{32} \mathrm{P}$, polyacrylamide gel electrophoresis of the reaction products, and autoradiography were performed according to a previously published protocol. ${ }^{28}$

Linkage between POAG and microsatellites was analysed using the computer program package LINKAGE version 5.2, ${ }^{29}$ assuming autosomal dominant inheritance with a disease allele frequency of 0.0001 and a phenocopy rate of 0.03 , and using locus distances from the genetic map of the human genome. ${ }^{27,30}$ Only individuals above 30 years of age were included in the analysis (34 subjects) (Figure 1), and a fixed penetrance of $75 \%$ was chosen for the linkage studies. ${ }^{10}$ Multipoint linkage analysis was performed using LINKMAP by recoding the marker alleles to a 4 -allele system and then doing two overlapping 5-point analyses.

\section{Results}

The individuals described in this study are members of a large family, most of whom live in the same village in Epirus, Greece. The POAG in this family appears to be transmitted in an autosomal dominant fashion (Figure 1). The age at diagnosis ranged from 33 to 77 years (Table 1). Whereas the patients of the older generation (II) were diagnosed at 54-77 years, the patients of the more recent generation (III) were diagnosed at 33-41 years (Table 1 ), probably due to the poor social conditions of the older generations living in an isolated region with lack of medical services. The exact age at onset of glaucoma in the patients is not known, as the disease is painless and progresses slowly.

The clinical findings of affected individuals included characteristic glaucomatous changes of the optic disc and the visual field. The cup to disc ratio of affected eyes was between 0.6 and 0.95 (mean 0.7) (Table 1). The difference in cup to disc ratio between the two eyes of an affected individual was $0-0.1$, showing an almost symmetrical progression of the disease in the two eyes. A relationship was found between the extent of the loss of visual field and the appearance of the optic disc and the cup to disc ratio. Gonioscopy did not show any signs of congenital, secondary or angle closure glaucoma. In all affected individuals the anterior chamber angle was open (grades III or IV). The intraocular pressure of affected individuals was more than $21 \mathrm{mmHg}$ before treatment (mean $31 \mathrm{mmHg}$ ) (Table 1). No refractive error was associated with the POAG. Topical medications were initially effective in controlling the intraocular pressure, but surgery (trabeculectomy) was usually required for long-term control (Table 1). Other

Table 1 Clinical findings in affected individuals

\begin{tabular}{|c|c|c|c|c|c|c|c|c|c|c|}
\hline \multirow[b]{2}{*}{ Pedigree no. } & \multirow[b]{2}{*}{ Age at diag. } & \multirow[b]{2}{*}{ Age at exam. } & \multicolumn{2}{|c|}{ Cup/disc } & \multicolumn{2}{|c|}{$I O P$} & \multicolumn{2}{|c|}{ Visual field } & \multicolumn{2}{|c|}{ Treatment } \\
\hline & & & $O D$ & OS & $O D$ & OS & $O D$ & OS & $O D$ & OS \\
\hline II-2 & 77 & 87 & 0.95 & 0.95 & 32 & 34 & S.D. & S.D. & Med+Trb & Med+Trb \\
\hline II-5 & 75 & 85 & 0.9 & 0.8 & 28 & 26 & M.D. & M.D. & Med+Trb & Med+Trb \\
\hline II-9 & 67 & 83 & 0.8 & 0.8 & 34 & 30 & M.D. & M.D. & Med+Trb & Med+Trb \\
\hline II-10 & 60 & 76 & 0.6 & 0.7 & 32 & 32 & M.D. & M.D. & Med+Trb & Med+Trb \\
\hline II-12 & 57 & 73 & 0.7 & 0.6 & 32 & 30 & M.D. & M.D. & Med+Trb & Med \\
\hline II-14 & 54 & 70 & 0.7 & 0.6 & 34 & 34 & M.D. & M.D. & Med & Med \\
\hline III-3 & 41 & 53 & 0.6 & 0.7 & 30 & 32 & M.D. & M.D. & Med & Med \\
\hline III-13 & 47 & 59 & 0.7 & 0.7 & 32 & 32 & M.D. & M.D. & Med & Med \\
\hline III-15 & 43 & 55 & 0.6 & 0.6 & 29 & 28 & M.D. & M.D. & Med & Med \\
\hline III-17 & 33 & 45 & 0.7 & 0.6 & 30 & 30 & M.D. & M.D. & Med & Med \\
\hline
\end{tabular}

Age at diag.=age at diagnosis; Age at exam=age at last exam; Cup/disc=vertical cup to disc ratio; OD=right eye; OS=left eye; $I O P=m a x i m a l$ intraocular pressure before treatment $(\mathrm{mmHg})$; Visual field=Humphrey 30-2; S.D.=severe defect; M.D.=moderate defect; Med=medical treatment; Trb=trabeculectomy. 
potential causes of visual field defects, including optic atrophy, optic neuropathy, retinal detachment, and diabetes mellitus, were excluded in these patients.

Linkage was established with a group of DNA markers located on chromosome 3q (Figure 2). Pairwise lod scores between POAG and chromosome $3 \mathrm{q}$ microsatellites are shown in Table 2 . The haplotype segregating with the POAG phenotype is shown in Figure 1. Multipoint linkage analysis gave a lod score of 3.80 at marker D3S1763 (penetrance 75\%). By examining different penetrance values, a maximal lod score of 3.88 was obtained at the same marker at a penetrance of $80 \%$. At a penetrance of $60 \%$, a multipoint lod score of 3.36 was obtained at marker D3S1744. The inclusion region comprised the interval between and outside the markers D3S3637 and D3S1763 (Figure 2).

Although the possibility of a founder effect between the family studied here and the previously reported GLC1C Oregon family is unlikely, we compared their genotypes at five microsatellite markers in the linked region (data not shown). Common alleles were present at D3S3612 and D3S1550 loci but not at D3S3694, D3S3599, and D3S1569.

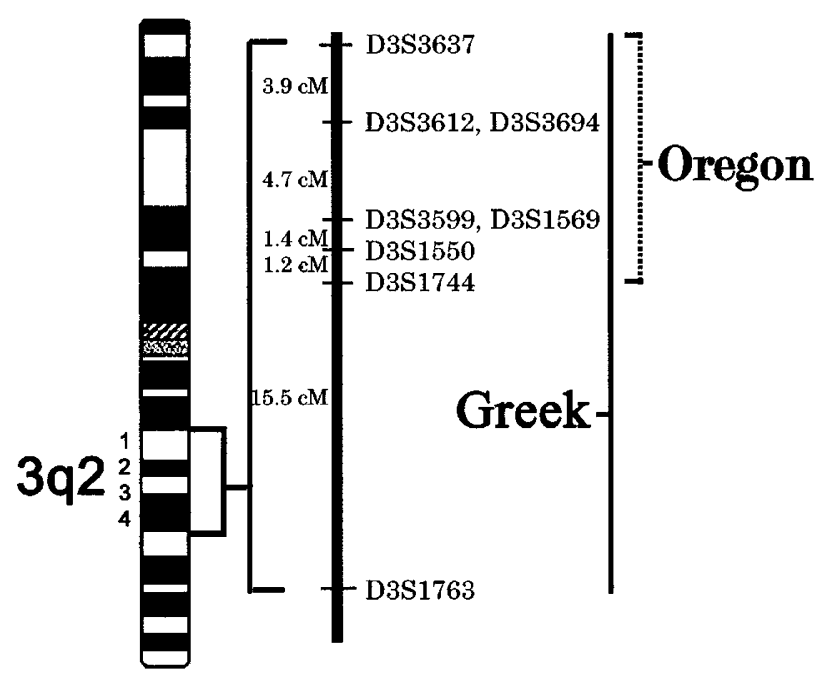

Figure 2 Chromosome $3 q$ ideogram showing inclusion region for the GLC1C locus and microsatellites studied in the Oregon and Epirus families. The distances between the markers are in $\mathrm{cM}$ using the Kosambi map function (sex-averaged map). ${ }^{30}$
D3S3612 and D3S1550 define the proximal and distal recombinational intervals of the GLC1C locus in the Oregon family. ${ }^{19}$ Therefore, there was no evidence for shared alleles within the most likely region of linkage in the two families.

\section{Discussion}

Five loci for autosomal dominant POAG have until now been localised to different human chromosomes. The GLC1B locus was mapped to the 2 cen-q13 region by linkage analysis in six UK Caucasian families. ${ }^{18}$ The disease onset was in the late 40 s (20-68 years, mean 47 years), and the intraocular pressure was moderately increased (mean $22 \mathrm{mmHg}$ ). The affected individuals showed a fair response to medical treatment, but $11 / 24$ patients needed surgery. The GLC1C locus was mapped to the 3q21-q24 region in one large North American Caucasian family that showed linkage to the D3S3637D3S1744 interval $(11.2 \mathrm{cM}) \cdot{ }^{19}$ The age at diagnosis was between 38 and 80 years (mean 56 years), and the intraocular pressure was moderately increased (mean $23 \mathrm{mmHg}$ ). The cup to disc ratio was $0.5-0.95$ (mean 0.75 ), and the patients showed a good response to medical therapy. The GLC1D locus was assigned to the $8 \mathrm{q} 23$ region in one large North American kindred segregating POAG of similar characteristics as described for the GLC1B and GLC1C families. ${ }^{20} \mathrm{~A}$ locus for normal tension OAG was mapped in one large British family to the 10p15-p14 region (GLC1E). ${ }^{21}$ The onset was in early to late adulthood (23-65 years, mean 44 years), with normal tension $(14-24 \mathrm{mmHg}$, mean $19 \mathrm{mmHg}$ ) and cup to disc ratio 0.5-0.95 (mean 0.8). The fifth locus, GLC1F, was mapped in one large North American family to 7q35q36, with age at diagnosis $25-70$ years (mean 54 years), cup to disc ratio $0.3-0.9$ (mean 0.7 ) and a mean intraocular pressure of $28 \mathrm{mmHg}^{22}$ Except from small variations in intraocular pressure, the phenotypic characteristics of the four POAG loci GLC1B, GLC1C, GLC1D, and GLC1F are quite similar, and they can not easily be distinguished based on clinical criteria. Only the GLC1B locus has so far been reported in more than one family, and the contribution of the different loci to POAG worldwide can only be determined when the underlying genetic defects become known and/or more families are described with linkage to the same regions. Their contribution also to sporadic cases of POAG remains to be elucidated.

Table 2 Pairwise lod scores between POAG and chromosome $3 q$ DNA microsatellites

\begin{tabular}{|c|c|c|c|c|c|c|c|c|}
\hline \multirow[b]{2}{*}{ Locus } & \multicolumn{8}{|c|}{ Lod scores at recombination fraction $\theta_{M=F}$} \\
\hline & 0.00 & 0.01 & 0.05 & 0.10 & 0.20 & 0.30 & $Z_{\max }$ & $\theta_{\text {max }}$ \\
\hline D3S3637 & 1.14 & 1.14 & 1.13 & 1.08 & 0.92 & 0.69 & 1.14 & 0.00 \\
\hline D3S3694 & 2.65 & 2.62 & 2.49 & 2.28 & 1.77 & 1.12 & 2.65 & 0.00 \\
\hline D3S1569 & 1.85 & 1.82 & 1.69 & 1.52 & 1.12 & 0.66 & 1.85 & 0.00 \\
\hline D3S1744 & 1.41 & 1.38 & 1.27 & 1.11 & 0.76 & 0.40 & 1.41 & 0.00 \\
\hline D3S1763 & 1.15 & 1.12 & 0.99 & 0.84 & 0.53 & 0.26 & 1.15 & 0.00 \\
\hline
\end{tabular}


We have established the most likely location of the autosomal dominant POAG locus segregating in a large Greek pedigree to be linked to the area of the microsatellite markers D3S3637 and D3S1763 on chromosome 3q21-q24. This corresponds to and confirms the GLC1C locus previously defined by linkage analysis in a single large Oregon pedigree. ${ }^{19}$ Using affected only-analysis we could not narrow down the inclusion region previously described in the Oregon family (Figure 2). The clinical features of POAG in the Greek family studied here are quite similar to the features of the GLC1C Oregon family. ${ }^{19}$

There is no evidence of reduced penetrance in the juvenile onset families. In our family five apparently unaffected individuals had inherited the disease haplotype: III-4, III-5, III-12, III-16, and III-23, aged 66, 63, 41, 53, and 37 years, respectively. These individuals will be closely monitored over the coming years for glaucoma symptoms. At the last examination (the year 2000) they all had normal cup to disc ratio (0.2-0.3), normal IOP and normal visual field. In addition, there are three unaffected individuals with a partial disease haplotype: III-14, III-18, and III-22, aged 54, 43, and 31 years, respectively. These latter individuals have the potential of narrowing the disease interval and will also be closely monitored over the next few years. Whereas individuals III-14 and III-18 at the last examination (the year 2000) had no glaucomatous changes, individual III-22 had a cup to disc ratio of 0.4 , IOPs 30 and $32 \mathrm{mmHg}$ (OD/OS), but normal visual fields, and was characterised as unknown in the linkage analysis. The exact penetrance will be defined only when the underlying genetic defect becomes known.

Although there is no known blood relationship between any of the members of the 11 pedigrees identified in Epirus, Greece, with the same kind of autosomal dominant POAG, ${ }^{12}$ it is most probable that the same genetic defect is segregating in this rural population of North Western Greece. The described pedigrees of 4-6 generations segregating POAG in an autosomal dominant fashion were native Greeks, inhabitants of Epirus. ${ }^{12}$ The previously reported GLC1C family living in Oregon ${ }^{19}$ was of English/Irish origin, with no known Greek ancestry, and haplotype analysis in the two GLC1C families demonstrated that the genetic defect most probably was of independent origin. It is hoped that further analysis in these and other families will eventually result in the identification of the disease causing genes, and thereby elucidating the pathogenesis of all types of OAG, enabling early diagnosis of individuals at risk, and therapy of this group of blinding disorders.

\footnotetext{
Acknowledgements

This work was supported by a grant from the American Health Assistance Foundation, grant G200014 (Drs Wirtz and Petersen) and by the Danish Biotechnology Programme, the Danish Cancer Society, the Danish Research Center for Growth and Regeneration, the Danish Environmental Research Programme, the Danish Research Council, Novo Nordisk Foundation, and Aage Bangs Foundation (Dr Tommerup).
}

\section{References}

1 Quigley HA: Open-angle glaucoma. N Engl J Med 1993; 328: $1097-1106$.

2 Coleman AL: Glaucoma. Lancet 1999; 354: 1803 - 1810.

3 Leske MC: The epidemiology of open-angle glaucoma: a review. Am J Epidemiol 1983; 118: 166-191.

4 Bonomi L, Marchini G, Marraffa M et al: Prevalence of glaucoma and intraocular pressure distribution in a defined population. The Egna-Neumarkt Study. Ophthalmology 1998; 105: $209-215$.

5 Wensor MD, McCarty CA, Stanislavsky YL, Livingston PM, Taylor HR: The prevalence of glaucoma in the Melbourne Visual Impairment Project. Ophthalmology 1998; 105: 733 - 739.

6 Wolfs RC, Borger PH, Ramrattan RS et al: Changing views on open-angle glaucoma: definitions and prevalences - The Rotterdam Study. Invest Ophthalmol Vis Sci 2000; 41: 3309 3321.

7 Tielsch JM, Sommer A, Katz J, Royall RM, Quigley HA, Javitt J: Racial variations in the prevalence of primary open-angle glaucoma. The Baltimore Eye Survey. JAMA 1991; 266: $369-$ 374.

8 Tielsch JM, Katz J, Sommer A, Quigley HA, Javitt JC: Family history and risk of primary open angle glaucoma. The Baltimore Eye Survey. Arch Ophthalmol 1994; 112: 69-73.

9 Wolfs RCW, Klaver CCW, Ramrattan RS, van Duijn CM, Hofman A, de Jong PTVM: Genetic risk of primary open-angle glaucoma. Population-based familial aggregation study. Arch Ophthalmol 1998; 116: $1640-1645$.

10 Posner A, Schlossman A: Role of inheritance in glaucoma. Arch Ophthalmol 1949; 41: 125-150.

11 Francois J: Genetics and primary open-angle glaucoma. Am J Ophthalmol 1966; 61: 652-665.

12 Kitsos G, Côté G, Psilas K: Un exemple d'hérédité dominante pour la transmission du glaucome primitif à angle ouvert dans une région du nord-ouest de la Grèce. J Fr Ophtalmol 1988; 11: $859-864$.

13 Sheffield VC, Stone EM, Alward WLM et al: Genetic linkage of familial open angle glaucoma to chromosome 1q21-q31. Nat Genet 1993; 4: $47-50$.

14 Stone EM, Fingert JH, Alward WLM et al: Identification of a gene that causes primary open angle glaucoma. Science 1997; 275 : $668-670$.

15 Kubota R, Noda S, Wang Y et al: A novel myosin-like protein (myocilin) expressed in the connecting cilium of the photoreceptor: molecular cloning, tissue expression, and chromosomal mapping. Genomics 1997; 41: 360-369.

16 Alward WLM, Fingert JH, Coote MA et al: Clinical features associated with mutations in the chromosome 1 open-angle glaucoma gene (GLC1A). N Engl J Med 1998; 338: 1022-1027.

17 Fingert JH, Héon E, Liebmann JM et al: Analysis of myocilin mutations in 1703 glaucoma patients from five different populations. Hum Mol Genet 1999; 8: 899-905.

18 Stoilova D, Child A, Trifan OC, Crick RP, Coakes RL, Sarfarazi M: Localization of a locus (GLC1B) for adult-onset primary open angle glaucoma to the 2cen-q13 region. Genomics 1996; 36: $142-150$.

19 Wirtz MK, Samples JR, Kramer PL et al: Mapping a gene for adultonset primary open-angle glaucoma to chromosome 3q. Am J Hum Genet 1997; 60: 296-304.

20 Trifan OC, Traboulsi EI, Stoilova D et al: A third locus (GLC1D) for adult-onset primary open-angle glaucoma maps to the 8q23 region. Am J Ophthalmol 1998; 126: $17-28$.

21 Sarfarazi M, Child A, Stoilova D et al: Localization of the fourth locus (GLC1E) for adult-onset primary open-angle glaucoma to the 10p15-p14 region. Am J Hum Genet 1998; 62: 641-652.

22 Wirtz MK, Samples JR, Rust K et al: GLC1F, a new primary openangle glaucoma locus, maps to 7q35-q36. Arch Ophthalmol 1999; 117: $237-241$

23 Wiggs JL, Allingham RR, Hossain A et al: Genome-wide scan for adult onset primary open angle glaucoma. Hum Mol Genet 2000; 9: $1109-1117$ 
24 Avramopoulos D, Kitsos G, Economou-Petersen E et al: Exclusion of one pedigree affected by adult onset primary open angle glaucoma from linkage to the juvenile glaucoma locus on chromosome 1q21-q31. J Med Genet 1996; 33: 1043-1044.

25 Spaeth GL: Primary (idiopathic) open-angle glaucoma. In: Eid TM, Spaeth GL (eds): The glaucomas: Concepts and Fundamentals. Philadelphia, Lippincott Williams \& Wilkins, 2000, pp. 89-103.

26 Budenz DL: Visual field in glaucoma. In: Parrish RK (ed): Atlas of Ophthalmology. Woburn, Butterworth-Heinemann, 1999, pp. $181-187$.

27 Dib C, Fauré S, Fizames C et al: A comprehensive genetic map of the human genome based on 5,264 microsatellites. Nature 1996; 380: $152-154$.
28 Eiberg H, Kjer B, Kjer P, Rosenberg T: Dominant optic atrophy (OPA1) mapped to chromosome $3 \mathrm{q}$ region. I. Linkage analysis. Hum Mol Genet 1994; 3: 977 -980.

29 Lathrop GM, Lalouel JM. Easy calculations of lod scores and genetic risks on small computers. Am J Hum Genet 1984; 36: $460-465$.

30 Broman KW, Murray JC, Sheffield VC, White RL, Weber JL. Comprehensive human genetic maps: Individual and sexspecific variation in recombination. Am J Hum Genet 1998; 63: $861-869$. 